\title{
Grain yield variation and association of major traits in brown-seeded genotypes of tef [Eragrostis tef (Zucc.)Trotter]
}

\author{
Habte Jifar ${ }^{{ }^{*}}$, Kebebew Assefa ${ }^{2}$ and Zerihun Tadele ${ }^{3}$
}

\begin{abstract}
Background: Tef [Eragrostis tef (Zucc.) Trotter] is the major cereal crop of Ethiopia where it is annually cultivated on more than three million hectares of land by over six million small-scale farmers. It is broadly grouped into white and brown-seeded type depending on grain color, although some intermediate color grains also exist. Earlier breeding experiments focused on white-seeded tef, and a number of improved varieties were released to the farming community. Thirty-six brown-seeded tef genotypes were evaluated using a $6 \times 6$ simple lattice design at three locations in the central highlands of Ethiopia to assess the productivity, heritability, and association among major pheno-morphic traits.

Results: The mean square due to genotypes, locations, and genotype by locations were significant $(P<0.01)$ for all traits studied. Genotypic and phenotypic coefficients of variations ranged from 2.5 to $20.3 \%$ and from 4.3 to 21.7 $\%$, respectively. Grain yield showed significant $(P<0.01)$ genotypic correlation with shoot biomass and harvest index, while it had highly significant $(P<0.01)$ phenotypic correlation with all the traits evaluated. Besides, association of lodging index with biomass and grain yield was negative and significant at phenotypic level while it was not significant at genotypic level. Cluster analysis grouped the 36 test genotypes into seven distinct classes. Furthermore, the first three principal components with eigenvalues greater than unity extracted $78.3 \%$ of the total variation.
\end{abstract}

Conclusion: The current study, generally, revealed the identification of genotypes with superior grain yield and other desirable traits for further evaluation and eventual release to the farming community.

Keywords: Brown seeded, Eragrostis tef, Heritability, Traits, Variation, Yield

\section{Background}

Tef [Eragrostis tef (Zucc) Trotter] is the most important cereal crop in Ethiopia where it is annually cultivated by 6.3 million small-scale farmers on more than $30 \%$ of the total area allocated to cereal crops [1]. The importance of tef in Ethiopia is mainly due to its preference by both farmers and consumers. Farmers, above all, grow tef due to its tolerance to several biotic and abiotic stresses especially to the poorly drained vertisols, a dominant soil type in the central highlands where other cereals can hardly survive without the use of proper drainage system. Over 50 million people in Ethiopia consume tef as

\footnotetext{
* Correspondence: habtejifar@gmail.com

${ }^{1}$ Holetta Agricultural Research Center, Ethiopian Institute of Agricultural

Research, P. O. Box 31, Holetta, Ethiopia

Full list of author information is available at the end of the article
}

staple food due to the better quality bread called "injera" made from it compared to that from other cereals. The absence of gluten in its grain [2] makes tef a healthy food such that people allergic to gluten can safely consume tef products. Compared to the straw from other cereals, the straw from tef is more nutritious and palatable for livestock feed $[3,4]$.

Despite its huge importance in the economy and being the favored crop by growers and consumers, the productivity of tef is relatively low compared to other cereals. In 2013, the national average yield for tef was only $1.4 \mathrm{t} /$ ha compared to $2.1 \mathrm{t} / \mathrm{h}$ a for wheat and $3.1 \mathrm{t} / \mathrm{ha}$ for maize [1]. The major yield limiting factors in tef are lodging and drought [5]. Lodging, the displacement of the plant from the upright position due to wind and rain, contributes for $17 \%$ yield loss in tef [6]. 
Based on the color of the grain, tef is broadly grouped into two classes as white- and brown-seeded types; however, grains with intermediate color between these also exist. Earlier, the National Tef Breeding Program in Ethiopia focused on improving the white-seeded tef based on consumers' preferences [7, 8]. The brown-seeded tef genotypes have been given less attention due to relatively lower market preferences and prices as compared to the white grain ones. As a result, only 4 out of the total of 35 improved tef varieties in Ethiopia are from the brown type [9]. Although brown grain tef is traditionally consumed by the farming community, recently, an increasing number of urban dwellers are becoming interested in this type of tef due to nutritional benefits especially high iron content [10]. The two tef types are mostly cultivated under similar environmental conditions, though the white type is vastly grown at an intermediate altitude below $2400 \mathrm{~m}$ a. s. 1 . while the brown type at altitudes above $2200 \mathrm{~m}$ a. s. 1 . However, farmers often claim that the brown-seeded types perform better under less favorable conditions of fields and cultural practices than do the white-seeded types [11]. The present study was, therefore, carried out to examine the performance of brown tef types for productivity and major agronomic traits at three locations in the central highlands of Ethiopia as well as to identify a new brown variety of tef for future release to the farming community.

\section{Materials and methods}

\section{Experimental sites and materials}

Field experiments were carried out during the main cropping season of 2013 at Holetta, Ginchi, and Adadi which are situated in the central highlands of Ethiopia. Climatic and soil-related descriptions of the three locations are shown on Table 1. Thirty-six brown-seeded tef lines including one farmer's cultivar for each locality (local check) and three released varieties (standard checks) were considered for the study (Table 2). Except

Table 1 Environmental descriptions of the three experimental locations in Ethiopia

\begin{tabular}{llll}
\hline & \multicolumn{2}{l}{ Locations } & \\
\cline { 2 - 3 } Descriptor & Holetta & Ginchi & Adadi \\
\hline Latitude & $09^{\circ} 03^{\prime} \mathrm{N}$ & $09^{\circ} 30^{\prime} \mathrm{N}$ & $08^{\circ} 31^{\prime} \mathrm{N}$ \\
Longitude & $38^{\circ} 30^{\prime} \mathrm{E}$ & $38^{\circ} 30^{\prime} \mathrm{E}$ & $38^{\circ} 13^{\prime} \mathrm{E}$ \\
Altitude (m a. s. I.) & 2400 & 2200 & 2383 \\
$\begin{array}{l}\text { Mean annual rain } \\
\text { fall (mm) }\end{array}$ & 1102 & 1139 & 1105 \\
$\begin{array}{l}\text { Mean annual } \\
\text { temperature }\left({ }^{\circ} \mathrm{C}^{\circ}\right)\end{array}$ & 14.5 & 16.3 & \\
Soil type & Light red & Black Vertisol & Light brown \\
Soil drainage & Well drained & Poorly drained & Well drained \\
Soil pH & 6.32 & 6.18 & 7.62 \\
\hline
\end{tabular}

Source: Keneni [29] the local and standard checks, the sources of all genotypes were lines derived from collection expeditions from 1984 to 1992 to seven diverse tef growing regions in the northern, southeastern, and central parts of Ethiopia by the Ethiopian Biodiversity Institute (EBI). The thirty-six tef lines were sown using $6 \times 6$ simple lattice design each on $2 \times 2 \mathrm{~m}$ plot. A fertilizer rate of 60 $\mathrm{kg}$ P2O5 and $60 \mathrm{~kg} \mathrm{~N}$ per hectare was applied for Adadi and Ginchi experimental sites while $60 \mathrm{~kg}$ P2O5 and $40 \mathrm{~kg} \mathrm{~N}$ per hectare was used for Holetta. The whole of the $\mathrm{P} 2 \mathrm{O} 5$ was applied in the form of diammonium phosphate (DAP) at planting time, while the remainder of $\mathrm{N}$ was applied in the form of urea at tillering about 30-40 days after planting depending on the climatic conditions of the experimental sites. All other cultural practices were made as per recommendations for each location.

\section{Data collection}

Data on days to panicle emergence, grain filling period, days to maturity, shoot biomass, grain yield, harvest index, and lodging index were assessed on plot basis. Harvest index was calculated as a ratio of grain yield to shoot biomass. On the other hand, plant height, panicle, and culm length were recorded on previously selected and tagged five random samples of plants from the central parts of each plot. Mean values of the five random samples of plants per plot were then used for the analyses of data collected on individual plant basis.

\section{Data analysis}

All the collected data were subjected to analysis of variance (ANOVA) using the SAS software [12], and variance effects were considered as significant and highly significant at $P<0.05$ and $P<0.01$, respectively.

The total phenotypic variance of each trait was partitioned into genetic and nongenetic factors using the variance component method based on the combined analyses over the three test locations as per the method suggested by Assefa et al. [13]. Phenotypic (PCV) and genotypic (GCV) coefficients of variation were calculated following the method of [14]. Broad sense heritability $(\mathrm{H})$ was calculated as a ratio of genotypic variance to phenotypic variance according to Allard [15]. Genetic advance (GA) was expected, assuming selection of the superior $5 \%$ of the genotypes were estimated following the procedure elaborated by Singh and Chaudhury [16].

Phenotypic and genotypic correlation coefficients were computed from the components of variance and covariances based on the method described by Singh and Chaudhury [16] using the CANDISC procedure of SAS system [12].

Multivariate analyses such as cluster analysis (CA) and principal component analysis (PCA) were made based on the mean values for the ten traits and 36 tef 
Table 2 List of tef genotypes or accessions used in the study

\begin{tabular}{|c|c|c|c|c|c|}
\hline No. & Name of genotype/pedigree & Area of collection & No. & Name of genotype/pedigree & Area of collection \\
\hline 1 & HO-TFS-5460A1 & Bale & 19 & HO-TFS-5442B1 & East Gojam \\
\hline 2 & HO-TFS-5452A1 & East Gojam & 20 & HO-TFS-5450B1 & East Gojam \\
\hline 3 & HO-TFS-5472A1 & South Wollo & 21 & HO-TFS-5503A1 & South Wollo \\
\hline 4 & HO-TFS-5459A1 & Bale & 22 & HO-TFS-5448B1 & East Gojam \\
\hline 5 & HO-TFS-5500A1 & East Gojam & 23 & HO-TFS-5493B1 & East Gojam \\
\hline 6 & HO-TFS-5431A1 & South Wollo & 24 & HO-TFS-5461B1 & Bale \\
\hline 7 & HO-TFS-5458B1 & Hadiya & 25 & HO-TFS-5485B1 & South Wollo \\
\hline 8 & HO-TFS-5450C 1 & East Gojam & 26 & HO-TFS-5451B1 & East Gojam \\
\hline 9 & HO-TFS-5469C 1 & South Wollo & 27 & HO-TFS-5500B1 & East Gojam \\
\hline 10 & HO-TFS-5448C 1 & East Gojam & 28 & HO-TFS-5507B1 & South Tigray \\
\hline 11 & HO-TFS-5483B1 & North Gonder & 29 & HO-TFS-5484A 1 & South Wollo \\
\hline 12 & HO-TFS-5449A1 & East Gojam & 30 & HO-TFS-5482A 1 & South Gonder \\
\hline 13 & HO-TFS-5431B1 & South Wollo & 31 & HO-TFS-5471A1 & South Wollo \\
\hline 14 & HO-TFS-5456C 1 & South Gonder & 32 & HO-TFS-5468C 1 & South Wollo \\
\hline 15 & HO-TFS-5499B1 & East Gojam & 33 & DZ-01-2053* & \\
\hline 16 & HO-TFS-5453A1 & North Gonder & 34 & DZ-01-99* & \\
\hline 17 & HO-TFS-5515E1 & East Tigray & 35 & DZ-01-1681* & \\
\hline 18 & HO-TFS-5435E2 & South Wollo & 36 & Local Check & \\
\hline
\end{tabular}

*Standard checks. The local check is the genotype (often a mixture) commonly grown by farmers in each locality

genotypes over the three locations. CA was made using the PROC CLUSTER of SAS Version 9 [12] following the average linkage cluster analysis, and the determination of the number of clusters was made based on the Pseudo-F and Pseudo- $\mathrm{T}^{2}$ options. PCA, on the other hand, was made using the PROC PRINCOMP of SAS version 9 [12] to identify the traits that contributed to the large part of the total variation among the genotypes. In principal component analysis, eigenvalues greater than unity were considered important to explain the observed variability.

\section{Results and discussions}

\section{Analysis of variance}

The combined analyses of variance over the three test locations revealed highly significant $(P<0.01)$ mean squares of locations and genotypes for all the traits evaluated (Table 3). Likewise, the interactions of genotypes with locations were highly significant $(P<0.01)$ for all traits except days to panicle emergence and lodging index which were only significant $(P<0.05)$. These significant effects due to genotype, locations, and genotype by environment interaction indicate that the genotypes

Table 3 Mean squares from ten traits of 36 tef genotypes evaluated at three locations in the central highlands of Ethiopia in 2013

\begin{tabular}{|c|c|c|c|c|c|c|c|c|}
\hline Traits & $\begin{array}{l}\text { Location }(\mathrm{L}) \\
(\mathrm{DF}=2)\end{array}$ & $\begin{array}{l}\text { Replication } \\
(\mathrm{DF}=1)\end{array}$ & $\begin{array}{l}\text { Genotypes }(\mathrm{G}) \\
(\mathrm{DF}=35)\end{array}$ & $\begin{array}{l}\text { Block (rep) } \\
(\mathrm{DF}=10)\end{array}$ & $\begin{array}{l}\mathrm{L} \times \mathrm{G} \\
(\mathrm{DF}=70)\end{array}$ & $\begin{array}{l}\text { Error } \\
(\mathrm{DF}=97)\end{array}$ & Mean & $\begin{array}{l}\text { CV } \\
(\%)\end{array}$ \\
\hline DPE & $2335.37^{* *}$ & $0.667 \mathrm{~ns}$ & $24.04^{* *}$ & 3.92 ns & $3.65^{*}$ & 2.35 & 60.40 & 2.54 \\
\hline DM & $15708.39 *$ & 0.907 ns & $29.68^{* *}$ & $3.92 \mathrm{~ns}$ & $16.24^{* *}$ & 3.08 & 118.64 & 1.48 \\
\hline GFP & $6316.51^{* *}$ & $0.907 \mathrm{~ns}$ & $10.30^{* *}$ & $5.73 \mathrm{~ns}$ & $18.76^{* *}$ & 4.70 & 58.28 & 1.48 \\
\hline $\mathrm{PH}$ & $855.04 * *$ & $31.97 \mathrm{~ns}$ & $139.26^{* *}$ & $9.21 \mathrm{~ns}$ & $23.18^{* *}$ & 5.40 & 86.32 & 2.69 \\
\hline$P L$ & $655.68^{* *}$ & $1.74 \mathrm{~ns}$ & $25.92^{* *}$ & $2.56 \mathrm{~ns}$ & $4.97^{* *}$ & 2.93 & 30.90 & 5.54 \\
\hline $\mathrm{CL}$ & $2387.19^{* *}$ & $25.01 \mathrm{~ns}$ & $55.24^{* *}$ & $3.64 \mathrm{~ns}$ & $13.37^{* *}$ & 2.93 & 55.37 & 3.09 \\
\hline SB & $5111.44^{* *}$ & $101.75 \mathrm{~ns}$ & $190.86^{* *}$ & $8.09 \mathrm{~ns}$ & $178.16^{* *}$ & 6.27 & 91.86 & 2.73 \\
\hline GY & $904.12^{* *}$ & $8.58 \mathrm{~ns}$ & $26.41^{* *}$ & $0.86 \mathrm{~ns}$ & $12.36^{* *}$ & 1.14 & 22.35 & 4.79 \\
\hline $\mathrm{HI}$ & $0.0989^{* *}$ & $0.00005 \mathrm{~ns}$ & $0.0015^{* *}$ & $0.00008 \mathrm{~ns}$ & $0.0009^{* *}$ & 0.00011 & 0.244 & 4.23 \\
\hline LI & $6453.34^{* *}$ & $9.80 \mathrm{~ns}$ & $90.80^{* *}$ & $9.74 \mathrm{~ns}$ & $62.60^{*}$ & 38.65 & 4.23 & 7.20 \\
\hline
\end{tabular}

CL culm length (cm), DM days to maturity (days), DPE days to panicle emergence (days), GFP grain filling period (days), GY grain yield (t/ha), HI harvest index (\%), $L /$ lodging index (\%), $P H$ plant height $(\mathrm{cm}), P L$ panicle length $(\mathrm{cm}), S B$ shoot biomass $(\mathrm{t} / \mathrm{ha})$

* and ${ }^{* *}$ significant at $P<0.05$ and $P<0.01$, respectively 
and locations were divergent to show substantial variations in useful agronomic traits for tef breeding. Similar results were also reported by Shiferaw and colleagues [17] for grain yield and yield-related traits.

The overall mean values of genotypes for all traits investigated were found to vary across the three experimental locations (Table 4). When the mean phenological traits across the three locations were compared, it took longer time for tef genotypes to flower and mature at Holetta than at Ginchi and Adadi. For instance, the grain filling period, which starts from the panicle emergence to grain maturity, took about 10 weeks at Holetta as compared to less than 8 weeks at both Ginchi and Adadi. This is mainly due to differences among the three locations in the climatic and geographical parameters, specifically temperature. Surprisingly, the minimum temperature at Holetta usually falls to around zero from October through December while it does not show significant change at the other two locations (Table 1).

Plant height which has direct relation with lodging index was significantly taller at Ginchi while panicle length which corresponds to grain yield of tef was significantly longer at Holetta than the two other locations. However, both grain and shoot biomass yields were significantly higher at Holetta than at Ginchi and Adadi mainly due to the lodging caused by unexpected rainfall during the grain filling stage especially at Ginchi.

The grain yield performances of most of the genotypes were not consistent across all locations except for HO-TFS-5499B1 and HO-TFS-5458B1 which were among higher yielding genotypes at both Ginchi and Holetta locations (Fig. 1). Four genotypes at Holetta, 12 at Ginchi, and 10 at Adadi gave higher yield than the check though some of them did not significantly $(P=0.05)$ give better yield than the best check.

Table 4 Mean values of 10 traits for 36 brown-seeded tef genotypes evaluated at three locations in the central highlands of Ethiopia in 2013

\begin{tabular}{llll}
\hline Traits & \multicolumn{3}{l}{ Locations* } \\
\cline { 2 - 4 } & Holetta & Ginchi & Adadi \\
\hline Days to panicle emergence & $66.8 \mathrm{a}$ & $56.0 \mathrm{c}$ & $58.4 \mathrm{~b}$ \\
Days to maturity & $135.7 \mathrm{a}$ & $110.1 \mathrm{~b}$ & $110.1 \mathrm{~b}$ \\
Grain filling period (days) & $69.0 \mathrm{a}$ & $54.0 \mathrm{~b}$ & $51.9 \mathrm{~b}$ \\
Plant height (cm) & $85.1 \mathrm{~b}$ & $90.2 \mathrm{a}$ & $83.7 \mathrm{c}$ \\
Panicle length (cm & $34.3 \mathrm{a}$ & $28.4 \mathrm{c}$ & $30.1 \mathrm{~b}$ \\
Culm length (cm) & $50.7 \mathrm{c}$ & $61.8 \mathrm{a}$ & $53.6 \mathrm{~b}$ \\
Shoot biomass (t/ha) & $9.8 \mathrm{a}$ & $9.6 \mathrm{~b}$ & $8.2 \mathrm{c}$ \\
Grain yield (t/ha) & $2.6 \mathrm{a}$ & $1.9 \mathrm{c}$ & $2.1 \mathrm{~b}$ \\
Harvest index & $0.27 \mathrm{a}$ & $0.20 \mathrm{c}$ & $0.26 \mathrm{~b}$ \\
Lodging index & $77.8 \mathrm{c}$ & $96.7 \mathrm{a}$ & $84.8 \mathrm{~b}$ \\
\hline
\end{tabular}

*Means in the same row followed by different letters are significantly different as judged by LSD at $P \leq 0.05$
The widely cultivated farmers' variety currently used as a local check at Holetta was among high yielders, only surpassed by HO-TFS-5458B1 and HO-TFS-5499B1. This could most probably be due to the fact that farmers themselves have developed such a high-yielding cultivar through years of selection and cultivation. The presence of this farmers' cultivar could also be the probable reason for a less adoption rate of the three so far nationally released brown-seeded varieties in the area. The two genotypes performed better than the farmers' cultivar in the current study, have a great potential to be released, and are accepted in the future by the farming community in the area.

\section{Estimates of coefficients of variation, heritability, and genetic advance}

The estimates of genotypic coefficient of variation (GCV) and phenotypic coefficient of variation (PCV), broad sense heritability (H), and expected GA are presented in Table 5 . The estimated values for GCV ranged from $2.7 \%$ for days to grain filling to $20.3 \%$ for grain yield per hectare, while the PCV estimates ranged from $4.3 \%$ for days to maturity to $21.7 \%$ for grain yield per hectare. The results of the current study are within the range of the previous report by Assefa et al. [18] but higher than those reported by Jifar [19] and Jifar et al [20]. The higher estimated values of PCV than GCV for all traits in the present study were in agreement with other findings $[18,21]$. This existence of high GCV among the lines indicates the possibility of making selection for some most important traits such as grain yield, panicle length, and harvest index. As PCV is usually the reflection of the effects of genotypes and environment, the higher PCV than GCV values suggests a significant contribution of environment and genotype by environment interactions to the expression of the traits under investigation.

On the other hand, the highest broad sense heritability value of $97 \%$ was estimated for days to panicle emergence followed by culm length, panicle length, and plant height, while the lowest value of $37 \%$ was recorded for grain filling period. This indicates that traits with high heritability can easily be selected based on phenotype. High heritability was also reported for panicle length [18] and for days to panicle emergence [21, 22] though the values for each trait were lower than those from the present findings.

The estimated genetic advance values in the present study ranged from $3.4 \%$ for grain filling period to $39.1 \%$ for grain yield. Seven of the 10 traits (grain yield, panicle length, plant height, harvest index, culm length, shoot biomass, and lodging index) have shown relatively high estimates of GA, indicating their amenability for improvement through selection. The GA estimates in the current study are much higher than those in most previous 

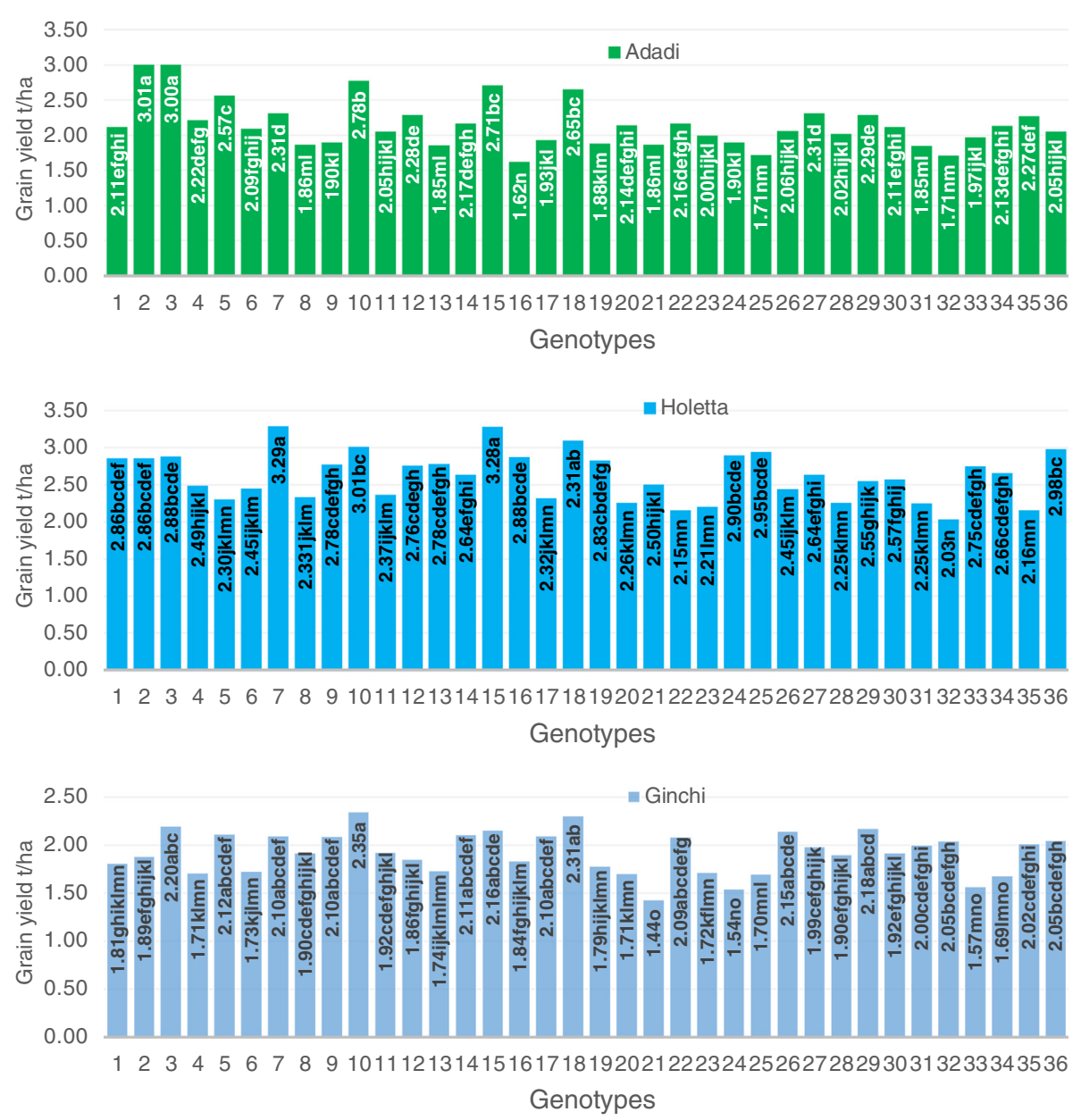

Fig. 1 The average grain yield of 36 brown-seeded tef genotypes at Holetta, Ginchi, and Adadi locations. Numbers of genotypes correspond to those described in Table 2. Genotypes followed by the same letter are not significantly different at $P<0.05$. Significant tests were made for each location

Table 5 Estimates of genotypic (GCV) and phenotypic (PCV) coefficient of variation, broad sense heritability $(\mathrm{H})$, and genetic advance as percent of the mean for 10 traits in 36 brown tef genotype evaluated in the central highlands of Ethiopia in 2013

\begin{tabular}{lllll}
\hline Traits & GCV (\%) & PCV \%) & H (\%) & GA (\%) \\
\hline Days to panicle emergence & 7.94 & 8.06 & 96.98 & 16.11 \\
Days to maturity & 4.01 & 4.33 & 85.59 & 7.64 \\
Days to grain filling & 2.70 & 4.47 & 36.62 & 3.37 \\
Plant height & 13.18 & 13.45 & 96.04 & 26.61 \\
Panicle length & 15.99 & 16.32 & 96.07 & 32.29 \\
Culm length & 12.71 & 13.10 & 94.11 & 25.40 \\
Shoot biomass & 11.10 & 13.24 & 70.24 & 19.15 \\
Grain yield & 20.31 & 21.74 & 87.31 & 39.10 \\
Harvest index & 13.63 & 14.85 & 84.32 & 25.79 \\
Lodging index & 9.85 & 10.66 & 85.35 & 18.74 \\
\hline
\end{tabular}

findings which ranged from less than 1 to $21 \%$ [18], less than 2 to $23 \%$ [21], and less than 1 to $15.8 \%$ [23] for other tef genotypes.

\section{Trait associations}

The phenotypic and genotypic correlations showed significant associations among most of the traits evaluated (Table 6). Grain yield showed highly significant $(P<0.01)$ and positive genotypic correlations with shoot biomass $(r=0.77)$ and harvest index $(r=0.74)$, while it was not significantly associated with the remaining traits. The highly significant and positive association between grain yield and that of shoot biomass and harvest index indicates the possibility of improving grain yield by improving any one of the two traits. The finding in the present study is in line with the previous report by Jifar et al. [20]. On the other hand, the phenotypic correlations between grain yield and all traits assessed were positive and highly significant except for plant height, culm length, and harvest index which revealed a negative and highly significant association. 
Table 6 Genotypic (upper diagonal) and phenotypic (lower diagonal) correlations among traits for 36 brown-seeded tef genotypes

\begin{tabular}{lllllllllll}
\hline Variable & DPE & GFP & DM & PH & PL & CL & SB & GY & $\mathrm{HI}$ \\
\hline DPE & 1 & $0.77^{* *}$ & $-0.22 \mathrm{~ns}$ & $0.60^{* *}$ & $0.59^{* *}$ & $0.54^{* *}$ & $0.13 \mathrm{~ns}$ & $-0.22 \mathrm{~ns}$ & $-0.46^{* *}$ & $-0.55^{* *}$ \\
DM & $0.89^{* *}$ & 1 & $0.44^{* *}$ & $0.64^{* *}$ & $0.55^{* *}$ & $0.64^{* *}$ & $-0.004 \mathrm{~ns}$ & $-0.31 \mathrm{~ns}$ & $-0.45^{* *}$ & $-0.42^{*}$ \\
$\mathrm{GFP}$ & $0.71^{* *}$ & $0.95^{* *}$ & 1 & $0.14 \mathrm{~ns}$ & $0.01 \mathrm{~ns}$ & $0.21 \mathrm{~ns}$ & $-0.21 \mathrm{~ns}$ & $-0.19 \mathrm{~ns}$ & $-0.08 \mathrm{~ns}$ & $0.10 \mathrm{~ns}$ \\
$\mathrm{PH}$ & $-0.02^{* *}$ & $-0.03 \mathrm{~ns}$ & $-0.04 \mathrm{~ns}$ & 1 & $0.91^{* *}$ & $0.96^{* *}$ & $0.08 \mathrm{~ns}$ & $-0.17 \mathrm{~ns}$ & $-0.34^{*}$ & $-0.47^{* *}$ \\
$\mathrm{PL}$ & $0.73^{* *}$ & $0.68^{* *}$ & $0.57^{* *}$ & $0.39^{* *}$ & 1 & $0.77^{* *}$ & $0.16 \mathrm{~ns}$ & $-0.10 \mathrm{~ns}$ & $-0.32 \mathrm{~ns}$ & $-0.43^{* *}$ \\
$\mathrm{CL}$ & $-0.46^{* *}$ & $-0.45^{* *}$ & $-0.40^{* *}$ & $0.82^{* *}$ & $-0.19^{* *}$ & 1 & $0.01 \mathrm{~ns}$ & $-0.20 \mathrm{~ns}$ & $-0.31 \mathrm{~ns}$ & $-0.44^{* *}$ \\
$\mathrm{SB}$ & $0.23^{* *}$ & $0.36^{* *}$ & $0.40^{* *}$ & $0.17^{*}$ & $0.14^{*}$ & $0.09 \mathrm{~ns}$ & 1 & $0.77^{* *}$ & $0.15 \mathrm{~ns}$ & $-0.12 \mathrm{~ns}$ \\
$\mathrm{GY}$ & $0.55^{* *}$ & $0.62^{* *}$ & $0.58^{* *}$ & $-0.22^{* *}$ & $0.40^{* *}$ & $-0.49^{* *}$ & $0.56^{* *}$ & 1 & $0.74^{* *}$ & $0.02 \mathrm{~ns}$ \\
$\mathrm{HI}$ & $0.44^{* *}$ & $0.41^{* *}$ & $0.34^{* *}$ & $-0.40^{* *}$ & $0.36^{* *}$ & $-0.64^{* *}$ & $-0.21^{* *}$ & $0.68^{* *}$ & 1 & $0.13 \mathrm{~ns}$ \\
LI & $-0.64^{* *}$ & $-0.56^{* *}$ & $-0.45^{* *}$ & $0.09 \mathrm{~ns}$ & $-0.57^{* *}$ & $0.44^{* *}$ & $-0.004 \mathrm{~ns}$ & $-0.42^{* *}$ & $-0.47^{* *}$ & 1 \\
\hline
\end{tabular}

$D P E$ days to panicle emergence, $D M$ days to maturity, GFP grain filling period (days), $P H$ plant height $(\mathrm{cm}), P L$ panicle length $(\mathrm{cm}), C L$ culm length $(\mathrm{cm}), S B$ shoot biomass (g/plot), GY grain yield (g/plot), $H I$ harvest index, LI lodging index

* and ** significant at $P \sim 0.05$ and $P \sim 0.01$, respectively

For traits with highly significant and negative association, the improvement of one trait would result in the reduction of another trait. Nevertheless, a lodging index, an important trait considered in tef improvement, showed a positive and significant phenotypic association with culm length while it had significant and negative association with all the remaining traits other than plant height and shoot biomass which had no significant association. The significant and positive phenotypic association reported currently for grain yield and phenologic traits is in line with previous reports [20] and contrary to the findings of Teklu and Tefera [24].

\section{Cluster analysis}

Except the local and the standard checks, all lines were collected from seven administrative zones of Ethiopia (about $75 \%$ from East Gojam and South Wollo Zones while $25 \%$ from the remaining five zones). Cluster analysis based on the means of three locations and 10 major quantitative traits grouped the 36 brown-seeded tef genotypes into seven distinct classes (Fig. 2). The number of genotypes in each cluster ranged from one in clusters VI and VII to 20 in cluster I. The farmers' cultivar (local check) and all the three improved varieties used as standard checks were all grouped into cluster I. The concentration of genetic diversity was also detected for the five administrative zones that have contributed for only $25 \%$ of the total lines as those lines were grouped under different clusters. Unlike the present findings, earlier studies grouped tef genotypes into four to six clusters [20,21, 25, 26].

The means of traits for the seven clusters in the present study are shown in Table 7. Cluster I consisted of 20 tef genotypes that have an average performance for all the traits under investigation. On the other hand, cluster II consisted of six genotypes, the second largest number. The genotypes in this group were characterized to have shorter length of panicle and culm as well as days to panicle emergence, lower biomass yield, and high values of harvest index and lodging index. Both cluster III and IV were found to have three genotypes each. The unique features of genotypes in cluster-III was longer days to grain filling and highest value of lodging index while those of cluster IV had higher grain yield and moderately low lodging index. Hence, genotypes from

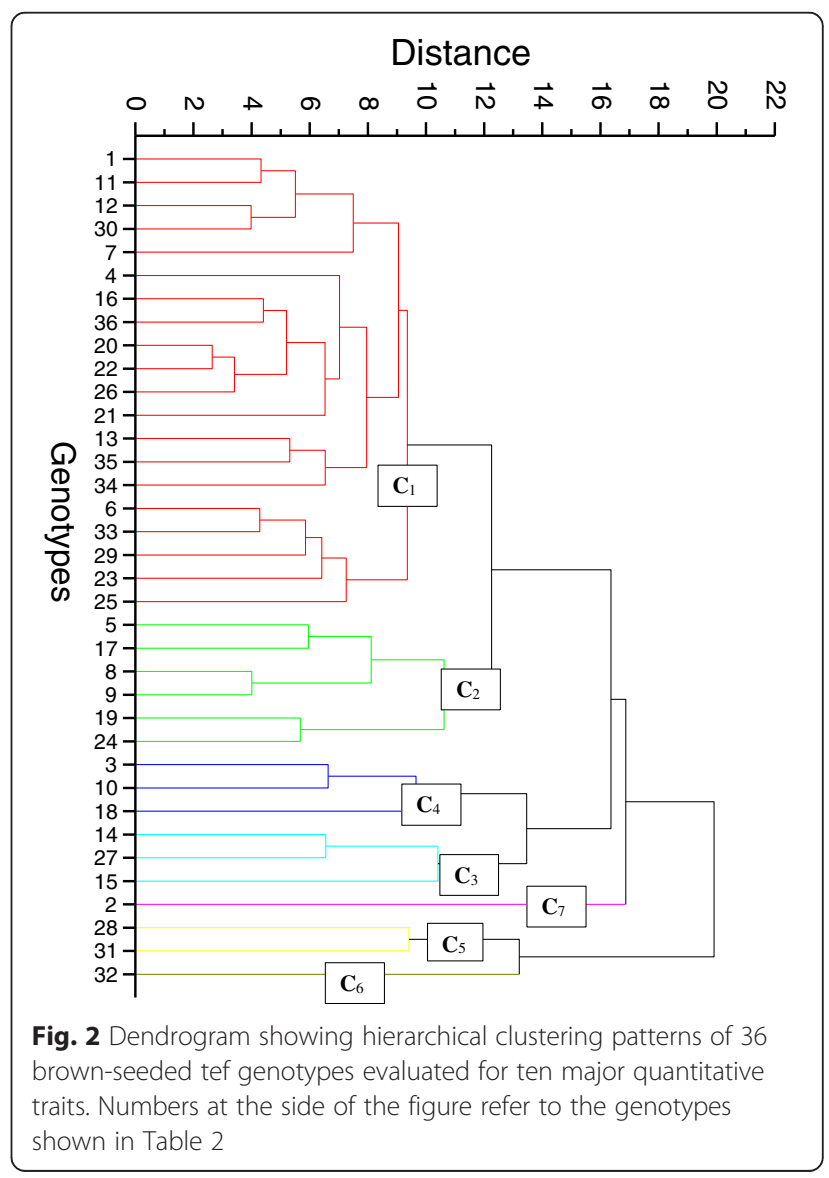


Table 7 Means for 10 different traits of 36 brown-seeded tef genotypes grouped into seven clusters

\begin{tabular}{|c|c|c|c|c|c|c|c|}
\hline \multirow[t]{2}{*}{ Trait } & \multicolumn{7}{|c|}{ Means of clusters } \\
\hline & $\mathrm{C}_{1}$ & $C_{2}$ & $C_{3}$ & $\mathrm{C}_{4}$ & $C_{5}$ & $\mathrm{C}_{6}$ & $C_{7}$ \\
\hline Days to panicle emergence & 61.1 & 57.83 & 59.00 & 62.00 & 63.00 & 63.00 & 58.00 \\
\hline Days to maturity & 119.2 & 116.50 & 118.33 & 119.33 & 122.50 & 120.00 & 113.00 \\
\hline Days to grain filling & 58.3 & 58.67 & 60.00 & 57.33 & 59.50 & 57.00 & 55.00 \\
\hline Plant height & 85.95 & 81.00 & 90.00 & 87.67 & 95.00 & 104.00 & 78.00 \\
\hline Panicle length & 30.75 & 28.33 & 33.00 & 31.67 & 34.00 & 38.00 & 29.00 \\
\hline Culm length & 55.05 & 52.67 & 57.00 & 56.33 & 61.00 & 66.00 & 49.00 \\
\hline Biomass yield & 90.7 & 86.50 & 98.33 & 105.00 & 88.00 & 89.00 & 99.00 \\
\hline Grain yield & 21.65 & 21.67 & 24.33 & 27.00 & 20.50 & 19.00 & 26.00 \\
\hline Harvest index & 0.241 & 0.253 & 0.247 & 0.257 & 0.250 & 0.220 & 0.260 \\
\hline Lodging index & 85.85 & 89.67 & 90.33 & 83.00 & 84.50 & 79.00 & 89.00 \\
\hline
\end{tabular}

cluster IV can be used for improvement of grain yield and total biomass. Cluster V, on the other hand, had longer phonological traits value and moderately high mean values for culm and panicle length. Surprisingly, cluster VI and VII were found to be solitary and had only one genotype in each cluster. The unique features of the genotype in cluster VI were longer days to panicle emergence, days to maturity and length of panicle, culm and plant height but lower values of grain yield, harvest index, and lodging index. On the other hand, the genotype in cluster VII had shorter days to panicle emergence and grain filling, shorter length of plant, culm and panicle, and higher yield of biomass and grain as well as harvest index. Hence, this particular genotype can be used for the improvement of harvest index and earliness traits.

\section{Principal component analysis}

The first three principal components (PCs) with eigenvalue greater than one contributed for $78.3 \%$ of the entire phenotypic variation observed among the 36 tef genotypes (Table 8 ). This was smaller than those from earlier reports which ranged between 80 to $85 \%$ [19, 26-28]. PC1 accounted for $44.7 \%$ of the variation among the test genotypes mainly due to the variation in plant height, culm length, days to panicle emergence, panicle length, and days to maturity, respectively. The contribution of PC1 in the present study was about $8 \%$ higher than the value reported for $\mathrm{PC} 1$ by $[26,27]$, but $23 \%$ lower than the value reported for $\mathrm{PC} 1$ by [28]. $\mathrm{PC} 2$, on the other hand, also accounted for $21.3 \%$ of the total variation among the test genotypes, whereby grain yield, shoot biomass, and harvest index traits were contributing majorly. $\mathrm{PC}_{3}$, on the other hand, has contributed for $12.3 \%$ of the total variation of the genotypes mainly resulting from variation in days to grain filling, days to panicle emergence, and harvest index.

\section{Conclusions}

Considerable grain trait variations were observed among the 36 tef genotypes evaluated at the three locations. There was also substantial genotype by environment interactions for all traits evaluated indicating that the test genotypes had differential performance at diverse locations. Besides, the test locations also showed substantial effects on all the traits studied indicating that the locations were adequately diverse to reveal the performance of the tef genotypes. The positive genotypic association between the grain yield, shoot biomass, and harvest index is a good opportunity to simultaneously improve those important agronomic traits. All phenologic traits including days to panicle emergence, days to maturity,

Table 8 Eigenvectors and values of the first three principal components for 36 tef test genotypes evaluated in the central highlands of Ethiopia in 2013

\begin{tabular}{llll}
\hline Traits & \multicolumn{3}{l}{ Eigenvectors } \\
\cline { 2 - 4 } & PC1 & PC2 & PC3 \\
\hline Days to panicle emergence & 0.3791 & 0.1068 & -0.3502 \\
Days to maturity & 0.3963 & -0.0636 & 0.1830 \\
Grain filling period & 0.0771 & -0.2647 & 0.7672 \\
Plant height & 0.4320 & 0.1191 & 0.1540 \\
Panicle length & 0.3971 & 0.1748 & 0.0410 \\
Culm length & 0.4131 & 0.0693 & 0.2223 \\
Shoot biomass & -0.0027 & 0.5758 & 0.0199 \\
Grain yield & -0.1782 & 0.6092 & 0.2146 \\
Harvest Index & -0.2659 & 0.3448 & 0.3139 \\
Lodging index & -0.2756 & -0.2082 & 0.1881 \\
Eigen value & 4.47 & 2.13 & 1.23 \\
Percent of variance accounted for & 44.7 & 21.3 & 12.3 \\
Cumulative variance accounted for (\%) & 44.7 & 66.0 & 78.3 \\
\hline
\end{tabular}


and grain filling period, and other traits like shoot biomass and harvest index are positively correlated with grain yield; these traits can be used as selection criteria for increased yield. On the other hand, of the three height-related traits including total plant height, culm length, and panicle length, the former two are negatively correlated and only panicle length is positively correlated with grain yield. Consequently, panicle length which has already been in use as indicator of high yield in the tef breeding program can still be used as useful selection criteria for yield. Cluster analysis had grouped the test genotypes into seven distinct classes with the larger number of genotypes (56 \%) fall under cluster I. Based on means of the clusters, different tef genotypes can be selected for improvement of traits of agronomic importance. For instance, tef genotypes in cluster IV can be used for improvement of grain yield and total biomass, while short stature plants for improving lodging resistance as well as for earliness traits can be made from genotype in cluster VII. Furthermore, the first three principal components with eigenvalue greater than one have contributed for $78 \%$ of the entire variation.

In general, the current study revealed the possibility of identifying lines with superior grain yield and other desirable traits for further evaluation and eventual release to the farming community. To this end, the materials would be valuable as a source of breeding materials for improved brown-seeded tef varieties which are expected to be in high demand, apart from use for domestic consumption, particularly in view of the presently burgeoning global popularity and export potential for tef and tef products.

\footnotetext{
Abbreviations

ANOVA: analysis of variance; $\mathrm{CA}$ : cluster analysis; $\mathrm{CL}$ : culm length; DAP: diammonium phosphate; DM: days to maturity; DPE: days to panicle emergence; EBI: Ethiopian Biodiversity Institute; EIAR: Ethiopian Institute of Agricultural Research; GA: genetic advance; GCA: genotypic coefficient of variation; GFP: grain filling period; GY: grain yield; HI: harvest index; LI: lodging index; PCV: phenotypic coefficient of variation; PH: plant height; PL: panicle length; SB: shoot biomass.
}

\section{Competing interests}

The authors declare that they have no competing interests

\section{Authors' contributions}

HJ designed the experiment and analyzed the data. HJ, KA, and ZT wrote the manuscript. All authors read and approved the manuscript.

\section{Author's information}

$\mathrm{HJ}$ is a researcher in Ethiopian Institute of Agricultural Research (EIAR) and a PhD student at Addis Ababa University, Addis Ababa, Ethiopia. KA is a Tef Research Program Coordinator in Ethiopian Institute of Agricultural Research, Debre Zeit, Ethiopia. ZT is a program leader in University of Bern, Institute of Plant Sciences, Altenbergrain 21, 3013 Bern, Switzerland.

\section{Acknowledgements}

The authors would like to acknowledge the Ethiopian Institute of Agricultural Research (EIAR) for financing the field research. We also thank the technical staff of the Tef Breeding Section at Holetta Agricultural Research Centers for the execution of the field experiments.

\section{Author details}

'Holetta Agricultural Research Center, Ethiopian Institute of Agricultural Research, P. O. Box 31, Holetta, Ethiopia. ${ }^{2}$ Debre Zeit Agricultural Research Center, Ethiopian Institute of Agricultural Research, P.O. Box 32 Debre Zeit, Ethiopia. ${ }^{3}$ Institute of Plant Sciences, University of Bern, Altenbergrain 21, 3013 Bern, Switzerland.

Received: 26 November 2014 Accepted: 8 May 2015

Published online: 16 June 2015

\section{References}

1. CSA. Agricultural Sample Survey 2012/2013 (2005 E.C.) Report on Area and Production of Major Crops (private peasant holdings, meher season), vol. I. Addis Ababa: Centeral Statistical Agency; 2013.

2. Spaenij-Dekking L, Kooy-Winkelaar Y, Koning F. The Ethiopian cereal tef in celiac disease. N Engl J Med. 2005;353(16):1748-9.

3. Bediye S, Sileshi Z, Mengistie T. Tef [Eragrostis tef (Zucc.) Trotter] Straw Quality as Influenced by Variety and Locations. In: Ethiopian Society of Animal Production: 18-19 April 1996. Addis Ababa: ESAP; 1996. p. 145-52.

4. Yami A. Tef Straw: A Valuable Feed Resource to Improve Animal Production and Productivity. In: Proceedings of the Second International Workshop: 7-9 November 2011; Debre Zeit. Bern: Ethiopian Institute of Agricultural Research, Addis Ababa and Institute of Plant Sciences, Bern University; 2013. p. 233-51.

5. Assefa K, Yu JK, Zeid M, Belay G, Tefera H, Sorrells ME. Breeding tef [Eragrostis tef (Zucc.) trotter]: conventional and molecular approaches. Plant Breed. 2011;130:1-9.

6. Ketema S. Tef (Eragrostis tef): Breeding, Genetic Resources, Agronomy, Utilization and Role in Ethiopian Agriculture. Addis Ababa: Institute of Agricultural Research (IAR); 1993.

7. Belay G, Tefera H, Tadesse B, Metaferia G, Jarra D, Tadesse T. Participatory variety selection in the Ethiopian cereal tef (Eragrostis tef). Expl Agric. 2005:42:91-101.

8. Belay G, Tefera H, Getachew A, Assefa K, Metaferia G. Highly client-oriented breeding with farmer participation in the Ethiopian cereal tef [Eragrostis tef (Zucc.) Trotter]. Afr J Agric Res. 2008;3(1):022-8.

9. MoA. Crop Variety Register Issue No. 17. Addis Ababa: Ethiopian Ministry of Agriculture, Plant Variety Release, Protection and Seed Quality Control Directorate; MoA; 2014

10. Mengesha M. Chemical composition of teff (Eragrostis tef) compared with that of wheat, barley and grain sorghum. Econ Botany. 1966;20(3):268-73.

11. Assefa $\mathrm{K}$, Tefera $\mathrm{H}$, Merker A. Variation and inter-relationships of quantitative traits in tef (Eragrostis tef (Zucc.) Trotter) germplasm from western and southern Ethiopia. Hereditas. 2002;136:112-6.

12. SAS. Property Software. 9th ed. Cary: SAS Institute; 2002.

13. Assefa K, Ketema S, Tefera H, Nguyen HT, Blum A, Ayele M, et al. Diversity among germplasm lines of the Ethiopian cereal tef [Eragrostis tef (Zucc.) Trotter]. Euphytica. 1999;106:87-97.

14. Burton GW, Devane EH. Estimation of heritability in tall Festuca (Festucaarundinacea) from replicated clonal material. Agron J. 1953;45:478-81.

15. Allard RW. Principles of Plant Breeding. New York: John Wiley \& Son; 1960.

16. Singh RK, Chaudhury BD. Biometrical method in quantitative genetic analysis. Kalyani: Ludhiana; 1996.

17. Shiferaw W, Balcha A, Mohammed H. Evaluation of drought tolerance indices in Tef [Eragrostis tef (Zucc.) Trotter]. J Agric Res. 2012;7(23):3433-8.

18. Assefa K, Ketema S, Tefera H, Kefyalew T, Hundera F. Trait diversity, heritability and genetic advance in selected germplasm lines of tef [Eragrostis tef (Zucc.) Trotter]. Hereditas. 2000;133:29-37.

19. Jifar H. Genetic Diversity and Association of Characters in Released Varieties of tef [Eragrostis tef (Zucc.)Trotter], M.Sc Thesis. Addis Ababa: Addis Ababa University; 2008.

20. Jifar H, Assefa K, Bekele E. Genetic variability in released tef [Eragrostis tef (Zucc.)Trotter] varieties of Ethiopia. In: Proceedings of the Thirteenth Biennial Conferences of Crop Science Society of Ethiopia: 31st Dec. 2008 -2nd Jan. 2009; Addis Ababa. Addis Ababa: Crop Science Society of Ethiopia; 2011. p. 160-9.

21. Assefa K, Tefera H, Merker A, Kefyalew T, Hundera F. Variability, heritability and genetic advance in pheno-morphic and agronomic traits of tef [Eragrostis tef (Zucc.) Trotter] germplasm from eight regions of Ethiopia. Hereditas. 2001;134:103-13. 
22. Tilhahun A, Zeleke $H$, Amsalu A. Genetic variability, heritability and genetic advance in tef (Eragrostis tef (Zucc.) Trotter) lines at Sinana and Adaba. Int J Plant Breeding Genet. 2012;6(1):40-6.

23. Tefera H, Assefa K, Hundera F, Kefyalew T, Tefera T. Heritability and genetic advance in recombinant inbred lines of tef (Eragrostis tef). Euphytica. 2003;131:91-6.

24. Teklu Y, Tefera H. Genetic improvement in grain yield potential and associated agronomic traits of tef (Eragrostis tef). Euphytica. 2005;141:247-54

25. Ebba T. Tef (Eragrostis tef) Cultivars: Morphology and Classification. Part II. Exp. Station. Bull. No. 66. Addis Ababa: Addis Ababa Univ., College of Agriculture, Dire Dawa; 1975.

26. Plaza SW, Cannarozzi G, Tadele Z. Genetic and phenotypic diversity in selected genotypes of tef [Eragrostis tef (Zucc.) Trotter. Afr J Agric Res. 2013;8(12):1041-9.

27. Assefa K, Merker A, Tefera H. Multivariate analysis of diversity of tef (Eragrostis tef (Zucc.) Trotter) germplasm from western and southern Ethiopia. Hereditas. 2003;138:228-36.

28. Adinew T, Ketema S, Tefera H, Sridhara H. Genetic diversity in tef [Eragrostis tef (Zucc.)Trotter] germplasms. Genet Resour and Crop Evol. 2005;52:891-902.

29. Keneni G. Genetic potential and limitations of Ethiopian chickpea (Cicer arietinum L.) germplasm for improving attributes of symbiotic nitrogen fixation, phosphorous uptake and use efficiency, and Aduzuki bean beetle (Callosobruchus Chinensis L.) resistance, PhD Thesis. Addis Ababa: Addis Ababa University; 2012

\section{Submit your next manuscript to BioMed Central and take full advantage of:}

- Convenient online submission

- Thorough peer review

- No space constraints or color figure charges

- Immediate publication on acceptance

- Inclusion in PubMed, CAS, Scopus and Google Scholar

- Research which is freely available for redistribution 